\title{
O jornalismo e as mediações: construção conceitual em sala de aula
}

Sabrina Moreira de Morais Oliveira

\section{Resumo}

A conceituação do jornalismo é marcada por intensas discussões teóricas. As diferentes definições e suas repercussões sociais demandam a avaliação de como ocorreria a construção do conceito de jornalismo em sala de aula. $\mathrm{O}$ objetivo deste estudo foi avaliar o desenvolvimento desse processo no primeiro ano do curso. Os conceitos de jornalismo formulados por diferentes autores e alunos foram analisados por meio de pesquisa bibliográfica e análise de questionários, respectivamente. Os resultados indicam relevante variabilidade dos conceitos propostos pelos alunos, além de mudanças substanciais ao longo do período do estudo. A pesquisa permitiu constatar a importância dos livros adotados na construção conceitual dos alunos e a complexidade deste processo em sala de aula.

Conceitos de jornalismo, Bibliografia da área, Sala de aula

\section{Journalism and mediation: conceptual construction in classroom}

\section{Abstract}

Intense theoretical discussions have taken part of the Journalism conception. Accordingly, their different definitions and social repercussions have required the evaluation of how this conceptual construction has been taken place inside the classroom. The aim of this study was to evaluate this process during their first academic year. The journalism conceptions described by different textbook authors and journalism students were evaluated through textbook search and questionnaire analysis, respectively. The results indicated a noteworthy variability of proposal concepts by the students; moreover, significant alterations could be observed during the period test. The obtained results allowed the corroboration of the significance of the evaluated textbooks in order to contribute to the student conception construction and the complexity of this process inside the classroom.

Keywords:

Journalism conception, Specific bibliography, Journalism classroom 


\section{Introdução}

A necessidade de uma discussão conceitual sobre o jornalismo já é apontada em diversas obras (ver Traquina: 2005). No caso da prática jornalística essa discussão não só diz respeito à constituição da identidade de uma área, pois essa prática envolve a noção de prestação de um serviço público vital para o sistema democrático. A chamada hipótese de agenda setting problematiza o papel desempenhado pelo jornalismo em relação às questões que afetam a sociedade diretamente, mas que não podem ser apreendidas na relação direta que o indivíduo estabelece com a realidade (Hohlfeldt, 2003).

Considerando o espaço acadêmico, um lugar privilegiado para a reflexão e a problematização sobre as questões profissionais, o presente trabalho analisou o conceito de jornalismo, explícito ou não, dos livros que integram a bibliografia básica de disciplinas específicas do primeiro ano do curso de jornalismo da Universidade Católica de Goiás e, através de questionários, o resultado da mediação do professor e dos colegas na tentativa de estabelecer conexões entre os elementos mediadores e a construção do conceito por parte dos alunos e de apresentar as mudanças verificadas no conceito de jornalismo de estudantes da área ${ }^{1}$.

\section{As categorias utilizadas na análise dos conceitos de jornalismo}

$\mathrm{Na}$ análise dos dados obtidos nos livros da bibliografia básica de disciplinas específicas do curso de jornalismo e das respostas dos alunos, foram utilizadas duas formas de categorização dos conceitos. Inicialmente, dois dos elementos que compõem o modelo matemático proposto por Shannon - emissão, transmissão - serão utilizados na nomeação dos grupos 1 e 2 (processo de produção e transmissão, respectivamente). As respostas que conceituam o jornalismo a partir da função social ou do efeito do jornalismo estão no grupo 3. Dos grupos 4 ao 7 foram criados grupos que combinavam os três primeiros grupos: grupo 4 - processo de produção e transmissão; grupo 5 - processo de produção e função social; grupo 6 - transmissão e função social; grupo 7 - processo de produção, transmissão e função social.

Algumas definições de jornalismo e as mudanças qualitativas nas respostas dos alunos exigiram a criação de novos grupos. No grupo 8, estão as repostas que mencionam as condições sociais. A partir do grupo 9 foram combinados os elementos dos três primeiros grupos e as condições sociais: grupo 9 - processo de produção e condições sociais; grupo 10 - condições sociais e transmissão; grupo 11 - condições sociais e função social; grupo 12 - processo de produção, condições sociais e transmissão; grupo 13 - processo de produção, condições sociais e função social; grupo 14 - condições sociais, transmissão e função social; grupo 15 - processo de produção, condições sociais, transmissão e função social.

${ }^{1} \mathrm{~A}$ análise sobre os conceitos dos alunos foi apresentada na $4^{\text {a }}$ Semana de Cultura e Cidadania da Universidade Católica de Goiás. Agradeço a aluna de iniciação científica, Líria Costa Rezende, e a professora Eliani Covem pela colaboração na coleta de dados. 
As condições sociais foram incorporadas a partir da proposta de Wolf (2003) sobre uma visão tripolar em relação ao processo de comunicação, definido a partir das relações estabelecidas entre os meios de comunicação, as condições sociais e a perspectiva do indivíduo.

\section{As definições de jornalismo nos livros}

Os livros analisados compõem a bibliografia básica das seguintes disciplinas do primeiro período do curso de jornalismo da Universidade Católica de Goiás: História do Jornalismo e Fotojornalismo. Do segundo período os livros que serão analisados são os adotados pelas disciplinas Produção e Redação Jornalística I e Telejornalismo I.

É possível verificar uma variação de objetos analisados pelos autores quando se referem ao jornalismo. Alguns não conceituam explicitamente o jornalismo. Nestes casos, foram levantados os aspectos que, segundo os autores, interferem no processo de produção da mensagem, a descrição de elementos que compõem esse processo ou que definem a função social do jornalismo.

Além disso, constatou-se uma gradação qualitativa em relação aos elementos que integram a análise sobre o jornalismo realizada pelos autores que compõem a bibliografia básica das disciplinas mencionadas. As perspectivas variam desde concepções centradas no processo de produção da mensagem, passando por aquelas que acrescentam a essa análise a preocupação com a função social, até àquelas que incorporam dois dos elementos indicados por Wolf (2003) como fundamentais na compreensão do processo de comunicação: as condições sociais e a perspectiva do indivíduo.

\section{Processo de produção}

Dentre os livros analisados, o de Hedgecoe (1996) apresenta uma peculiaridade: trata-se de um manual para fotógrafos, o que explica a ausência de referências ao jornalismo. Ainda assim, é possível considerar que suas prescrições para os fotógrafos influenciem os leitores de seu guia. Hedgecoe considera que "é mais importante aprender a ver e a compreender do que simplesmente olhar" (p. 06). Mas essa compreensão não significa o questionamento da noção de imparcialidade. $\mathrm{O}$ autor afirma que "aprender a extrair o máximo da fotografia significa ver o mundo à sua volta com a mesma imparcialidade da objetiva e do filme" (p. 38). O guia também descreve técnicas que evocam com mais fidelidade a atmosfera e a atração da natureza. As técnicas são usadas para transmitir as intenções e interpretações do fotógrafo, para acrescentar realismo à fotografia. Segundo Hedgecoe, o fotógrafo deve usar grande variedade de ângulos e/ou objetivas, para revelar os
É possível verificar

uma variação de objetos analisados pelos autores quando se referem ao jornalismo. Alguns não conceituam explicitamente o jornalismo 
diversos aspectos de um mesmo tema. Pode-se concluir que, para o autor, o trabalho do fotógrafo é interpretativo, de construção de uma representação mais ou menos próxima da realidade. Esse processo de aproximação se constrói a partir dos objetivos do fotógrafo e de sua sensibilidade.

\section{Processo de produção e função social}

Outros autores também centram suas análises no trabalho do jornalista, considerando a sua ação no processo de produção, mas acrescentam a esse processo as questões organizacionais e a função social do jornalismo. Em relação a esse papel social, as análises estabelecem a ligação entre jornalismo e democracia.

No livro de Morais (1994) é possível depreender o conceito de jornalismo assumido pelo personagem de sua biografia: Assis Chateaubriand. Para o dono dos Diários Associados, o trabalho do jornalista é o de descrever e a função dos jornais é a de promover o progresso. Chateaubriand (1919:108) afirma: "Nós, jornalistas, não passamos de índoles descritivas. Somos no máximo coloristas dos fatos, se quiserem, mas nunca, jamais, criaturas de imagens e de idéias". Em outro trecho, o jornalista (1931: 265) afirma:

Federado aos Associados, o Diário de Pernambuco conservará intata sua autonomia para exercer o mandato que lhe outorgou o povo de Pernambuco. Onde quer que haja um erro a profligar, um abuso de autoridade a denunciar, ele jamais fugirá a esse dever.

A função social do jornalismo também é mencionada por Curado. Segundo a autora (2002: 12), “o jornalismo é um caminho que nos leva a desvendar segredos que, se revelados, ajudam a melhorar as condições da vida coletiva”. Nesse processo de desvendamento e revelação, a autora afirma que o jornalismo busca a verdade visando informar. A verdade jornalística é definida por Curado como o fato em toda a sua extensão. A autora também destaca a atualidade como um critério definidor do jornalismo.

Na análise de Sherwood (1981), a prática jornalística é vinculada explicitamente à democracia. O autor afirma que

o jornalismo, em geral, e jornais, em particular, estão na dianteira dos órgãos que defendem as nossas liberdades fundamentais e resguardam a nação contra a tirania, a corrupção e o abandono do dever. E divulgar notícias desfavoráveis a quem quer que seja, sem temor nem favor, é uma das mais poderosas armas do jornalismo. (ibidem: 115).

Além das prescrições que orientam o trabalho do jornalista, Sherwood menciona as questões organizacionais que, igualmente, condicionam a produção jornalística e que, segundo o autor, às
Outros autores também centram suas análises no trabalho do jornalista, considerando a sua ação no processo de produção, mas acrescentam a esse processo as questões organizacionais e a função social do jornalismo 
vezes, são definidas pelo departamento de publicidade. Em relação à atuação do repórter, o autor afirma que, ao cumprir o papel de estabelecer a relação entre as fontes de informação e os leitores, o jornalista deve resistir ao impulso de fazer julgamentos em relação aos seus entrevistados (a entrevista é o gênero jornalístico privilegiado pelo autor) para não tirar o equilíbrio da reportagem. Em seguida, Sherwood amplia suas considerações para englobar outros gêneros do jornalismo: "Se um senso de equilíbrio e proporção é necessário para entrevistar alguém, é igualmente necessário para avaliar acontecimentos e situações.” (idem). Como considera que todo jornalista carrega sua carga de preconceitos, o autor afirma que o repórter deve se esforçar "para ver tudo com olhos puros e ouvir tudo com ouvidos imparciais." (ibidem).

Erbolato (1991) também considera que, na produção da notícia, atuam elementos ligados ao jornalista, à empresa, que possui seus critérios e preferências por determinados assuntos. A atuação dos jornalistas compreende a seleção das notícias, a produção de um texto compreensível, que motive a leitura. Outra característica da notícia mencionada por Erbolato é a objetividade. Segundo o autor (op. cit.: 56), a notícia

deve ser publicada de forma sintética, sem rodeios e de maneira a dar a noção correta do assunto focalizado. Quem colhe dados, observando o local ou entrevistando pessoas capacitadas a proporcionar informações para a matéria, deve agir com isenção de ânimo. Honestidade e imparcialidade são atributos exigidos do repórter. Porém o poder de síntese não impedirá a clareza.

Erbolato afirma que o relato e a descrição do fato devem ser produzidos dentro dos limites de objetividade permitidos pela natureza humana.

Em relação ao papel social do jornalismo, Erbolato considera que ele cumpre uma função informativa, que pode apresentar desdobramentos sobre os hábitos, as condições de vida e sobre os níveis conscientes ou subconscientes do receptor. Mas o autor estabelece um sistema de influências em que o público também atua sobre a produção jornalística, uma vez que a independência do jornal está vinculada à estabilidade econômica que, por sua vez, depende da credibilidade junto aos leitores e aos anunciantes.

Paternostro (1999) também vincula a produção jornalística às expectativas do público. A autora estabelece um vínculo entre a produção do telejornal, os condicionamentos impostos pela ampla difusão, pela efemeridade e pela necesside de imagens, e o condicionamento estabelecido pelo público. Condicionamento que é explicado a partir do índice de audiência que "orienta a programação e cria condições de sustentação comercial” (ibidem: 65).
Erbolato afirma que o relato e a descrição do fato devem ser produzidos dentro dos limites de objetividade permitidos pela natureza humana. 
$\mathrm{Na}$ apresentação de seu livro, Paternostro (1999) enumera as funções da televisão: influencia atitudes, determina valores, muda comportamentos, redireciona caminhos, questiona posturas, revela avanços, denuncia atrocidades, discute, analisa, comenta, explica, informa, ensina, entretém, deseduca, emociona, choca, revolta, entristece e alegra, estimula e provoca o interesse e a necessidade de se ampliar o conhecimento sobre os fatos. Considerando o poder assustador da televisão, a autora afirma que é preciso que valores muito sólidos estejam presentes em quem o exerce. Paternostro afirma que a mensagem depende da razão e da emoção do jornalista e por isso sua prescrição é a de que se trabalhe com independência, honestidade, isenção, imparcialidade, ética e respeito ao ser humano. Segundo a autora, "a busca da verdade não termina jamais!" (ibidem: 62).

Teles (1986), ao contar a história da imprensa goiana, fala do trabalho do repórter como o de um narrador e dos jornais como propagadores de informações. O autor contrapõe o jornalista do passado ao da atualidade. No passado, o jornalista era, segundo Teles, senhor absoluto do pensamento e da verdade e, na atualidade, apenas uma peça da anônima e complicada engrenagem de comunicação. O autor cita várias passagens do jornal Matutina Meia-Pontense que vinculam o jornalismo à democracia. Em um dos trechos reproduzidos, lê-se: (...) Nos Estados submetidos ao regime constitucional e representativo, a publicidade, por via da imprensa, é a grande mola, a alma do governo. A Matutina $\mathrm{n}^{\circ}$ 250. (p. 79). Em outro:: (...) a Imprensa livre, ela é antemural e o fiador de todas as nossas instituições, ela é finalmente um estabelecimento sem o qual não se pode contar com a liberdade. $A$ matutina $\mathrm{n}^{\circ}$ 85. (p. 97).

\section{Processo de produção, condições sociais e função social}

Nas próximas definições, os autores mencionam, além de características do processo de produção, as condições sociais nas quais se realiza essa produção. As funções sociais do jornalismo também integram as concepções dos autores.

Sousa (2005) caracteriza o jornalismo pelas funções que ele exerce na sociedade democrática e pelos fatores que interferem na construção da notícia, desde as idiossincrasias de um jornalista, passando pelos recursos, as fontes usadas, as rotinas de trabalho até os condicionamentos da profissão. Segundo o autor, seu livro é "um manual que pugna pelo rigor, pelo compromisso com a realidade, pela honestidade, pela intenção de verdade, pela riqueza do pluralismo de visões de mundo" (p. 06). O jornalismo, na concepção proposta por Sousa, seleciona e hierarquiza a informação que deve ser construída com a independência e a isenção possíveis. A independência e isenção, no entanto, não excluem o fato

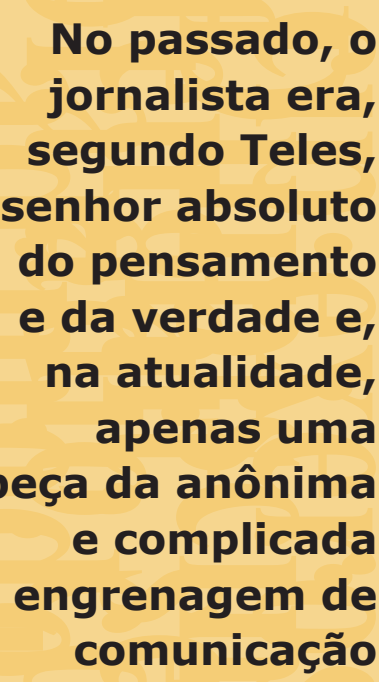

No passado, o jornalista era, segundo Teles, senhor absoluto do pensamento e da verdade $e_{\text {, }}$ na atualidade, da anônima grenagem de comunicação 
de que cada empresa ter a sua própria cultura e ideologia. Em relação às funções exercidas pelo jornalismo, o autor afirma que os jornais são os vigilantes dos poderes constituídos na democracia, que eles trazem para o espaço público os assuntos que são socialmente relevantes, que podem contribuir para a formação dos seus leitores e podem ter uma função de prazer, distração e entretenimento.

Para Barbeiro e Lima (2002), o jornalismo resulta de um processo de construção coletiva, em que se destacam fatores como a ética, as questões organizacionais e as leis do mercado. Segundo os autores, os jornalistas

elegem um norte que possa guiá-los através da sua frágil independência em suas relações com os diversos poderes, as negligências na verificação das informações sob a influência conjugada das leis do mercado, da velocidade da informação, da eficiência dos comunicadores. (ibidem: 20).

A objetividade é questionada, pois, considera-se que os fatos são apreendidos a partir da subjetividade dos jornalistas. Ainda que assim considerem, os autores afirmam que o compromisso do jornalista é com a verdade. Aqui, como nos outros autores, as funções do jornalismo estão intrinsecavelmente ligadas à manutenção da democracia.

Se, até o momento, o jornalismo é tido como elemento mantenedor da democracia, na análise proposta por Sodré (2002), as condições sociais, as relações capitalistas, constituirão uma nova função para o jornalismo. O autor, ao descrever e analisar a história da imprensa no Brasil, contrapõe a imprensa artesanal à imprensa industrial. Segundo o autor, "a imprensa artesanal vivia da opinião dos leitores e buscava servi-la; na imprensa industrial já isso não acontecia, o jornal dispensa, no conjunto, a opinião dos leitores e passa a servir aos anunciantes, predominantemente." (XIII). Os jornais são definidos como meios que vendem informação e, para o autor, quem controla a informação, controla o poder. Sodré também critica a relação entre a imprensa e o neoliberalismo, pois considera que "quando a imprensa, como aqui e agora, modula um coro repetitivo de louvação ao neoliberalismo, está claro e evidente que perdeu a sua característica antiga de refletir a realidade." (XVII).

\section{Processo de produção, condições sociais e perspectiva do indivíduo}

Nas duas últimas obras analisadas, ambas da disciplina $F_{O}$ tojornalismo, a concepção sobre a fotografia, em particular, permite integrar na análise sobre o processo de comunicação, além de características da produção da mensagem e das condições sociais, a perspectiva do indivíduo. 
Ivan Lima (1988) considera que a fotografia é um meio de expressão do emissor, ligado de forma consciente ou inconsciente a uma corrente ideológica e/ou movimento artístico, e é produtora de uma imagem que é lida e interpretada pelo receptor. O autor menciona que a fotografia utilizada na imprensa tem caráter e predominância informativa. Ainda que possua essa característica, Lima contrapõe o foco da imprensa capitalista no impacto que a fotografia pode causar, o que aumentaria a venda dos jornais, ao que, segundo ele, representa o papel da fotografia no jornalismo que é o de "transmitir a informação esgotando suas possibilidades, ou seja, adquirindo também um caráter estético e transmitindo valores culturais" (p. 24). O autor caracteriza essa transmissão como expressão do ocorrido de forma clara e indiscutível. Além disso, a transmissão deve situar o fato, o evento ou o acontecimento dentro do seu espaço e da sua época. Lima considera que a fotografia acentua o realismo, sendo possível perceber uma proibição de contestação da imagem obtida, e a presença do jornal no acontecimento. Além de passar a informação com clareza, o uso de técnicas específicas também permite acentuar a dramaticidade da imagem, a construção de impressões de repouso, de profundidade, de frieza, entre outras.

No livro de Arlindo Machado (1984), por sua vez, existe uma problematização sobre um dos conceitos que marcam muitas definições do jornalismo - ver Traquina (2005) e Oliveira (2006): o conceito de objetividade. O autor mostra que historicamente se constituiu a noção de um sujeito transcedental, entendido como uma consciência que dá origem ao sentido. Ao invés de se considerar que a fotografia compreende a construção de um signo que reflete e refrata a realidade, Machado explica que a ênfase sobre o processo de reprodução oculta todo processo mediador. $\mathrm{O}$ autor identifica nesse processo o papel ideológico da fotografia de elemento universal, de olho absoluto que apaga o próprio processo de produção, deixando de reconhecê-lo como transformação da realidade em fatos de cultura, em signos.

Esse percurso indica que, apesar das especificidades, nas concepções de jornalismo das diferentes obras que integram a bibliografia básica das disciplinas aqui analisadas, predominam o processo de produção e a função social. As condições sociais integraram as concepções de jornalismo em três obras, mas sua presença estava ligada ao processo de produção e à função social. O processo de produção, como único elemento, e a visão tripolar proposta por Wolf (2003) vão compor muito mais a definição de fotografia do que de jornalismo. Ainda assim, pode-se considerar que a presença da fotografia nos jornais permite uma vinculação entre a definição de fotografia e a definição de jornalismo.
Apesar das especificidades, nas concepções de jornalismo das diferentes obras que integram a bibliografia básica das disciplinas aqui analisadas, predominam o processo de produção e a função social 


\section{As definições de jornalismo sem a mediação acadêmica}

$\mathrm{Na}$ caracterização da visão dos alunos ingressantes no curso, foram analisadas quarenta e cinco respostas. O material analisado indicou que, nas respostas dos alunos que às vezes contam apenas com sua vivência e com o senso comum, o jornalismo é definido a partir do processo de transmissão (11 respostas). As respostas consideram que o jornalismo mostra a realidade, repassa, divulga, informações, expande notícias, leva conhecimento, informações, apresenta notícias, fatos, opiniões, mostra o cotidiano.

A função social e o processo de produção também foram mencionados em muitas repostas, 8 e 7 , respectivamente. Entre as funções sociais mencionadas, destacam-se: corresponder a interesses da sociedade, manter o mundo informado, denunciar e alertar, conscientizar, ajudar a sociedade a se tornar mais justa. As respostas que se referem ao processo de produção definem o jornalismo a partir das mensagens formuladas pelos jornais. Segundo essas respostas, jornalismo são os fatos. Em uma das respostas, o aluno considera que jornalismo são os fatos reais. Nessas definições, também considera-se que o jornalismo é a busca da verdade, a fuga da rotina, o estudo de como passar a informação, o cotidiano, uma profissão, a procura de vários ângulos do mesmo fato.

Já nesse momento, aparecem respostas que mencionam mais de um elemento na definição do jornalismo. Nove respostas mencionaram a transmissão e a função social. Enquanto cinco respostas se centraram no processo de produção e na função social. Ainda que em menor número, três repostas mencionaram o processo de produção e a transmissão na definição do jornalismo e duas respostas mencionaram o processo de produção, a transmis são e a função social. Nesse caso, o jornalismo é definido como captador, transmissor, de assuntos formadores de opinião.

Essas são caracterizações que ainda não passaram pelos processos de mediação acadêmicos. No caso aqui analisado, a mediação propiciada pela bibliografia de algumas disciplinas específicas do curso e pela atuação de professores e colegas de classe. Em seguida, vamos apresentar os resultados da aplicação de três questionários que foram respondidos pelos alunos do segundo período do curso antes e depois desses processos de mediação.

\section{As definições de jornalismo em três momentos}

O mesmo questionário aplicado aos alunos do primeiro período também foi respondido pelos alunos do segundo período no primeiro dia de aula da disciplina Teoria da Comunicação. As respostas analisadas (42), nesse primeiro momento, já mostram as mudanças qualitativas em relação ao conceito de jornalismo.
O material analisado indicou que, nas respostas dos alunos que às vezes contam apenas com sua vivência e com o senso comum, o jornalismo é definido a partir do processo de transmissão 
O maior número de respostas (dezessete) aparece no grupo 4. Nesse grupo, estão as respostas que definem o jornalismo a partir do processo de produção e da transmissão. Sete respostas mencionaram os três elementos: processo de produção, transmissão e função social.

O grupo 5 (processo de produção e função social) e o grupo 6 (transmissão e função social) contam com três e duas respostas, respectivamente. Os três primeiros grupos, que integraram o maior número de respostas dos alunos ingressantes, já não concentram o maior número de definições do jornalismo. Enquanto nove respostas mencionaram a transmissão, três mencionaram o processo de produção e uma a função social.

O segundo questionário, aplicado logo depois da leitura do texto A influência do jornalismo de P. Bourdieu (1997), revelou novas mudanças qualitativas. O pólo representado pelas condições sociais exigiu a criação de novos grupos. A partir dele (grupo 8) foram organizadas as seguintes combinações: grupo 9 - processo de produção e condições sociais; grupo 10 - condições sociais e transmissão; grupo 11 - condições sociais e função social; grupo 12 - processo de produção, condições sociais e transmissão; grupo 13 - processo de produção, condições sociais e função social; grupo 14 - condições sociais, transmissão e função social; grupo 15 - processo de produção, condições sociais, transmissão e função social.

Nesse momento, a maioria das respostas, de um total de 24, definiu o jornalismo a partir do processo de produção e das condições sociais (sete respostas). Outras seis respostas mencionaram o processo de produção, as condições sociais e a função social quando conceituaram o jornalismo. Em duas respostas, foram mencionados o processo de produção e a transmissão.

As categorias que contaram com apenas uma resposta foram: condições sociais; condições sociais e transmissão; processo de produção, condições sociais e transmissão; condições sociais, transmissão e função social. Nenhuma resposta foi incluída nos grupos 5 (processo de produção e função social), 6 (transmissão e função social), 7 (processo de produção, transmissão e função social), 11 (condições sociais e função social) e 15 (processo de produção, condições sociais, transmissão e função social).

Outro número que revela a mundança qualitativa é o de respostas que definem o jornalismo a partir de um único elemento. Apenas cinco respostas se encontram nesta situação e mencionam o processo de produção. Nenhuma resposta se refere somente à transmissão ou somente à função social.

O último questionário, que voltava a fazer a mesma pergunta do primeiro (Como você define o jornalismo?), mostra dois resultados significativos para o presente trabalho: o número de re-
Outro número que revela a mundança qualitativa é o de respostas que definem $o$ jornalismo a partir de um único elemento. Apenas cinco respostas se encontram nesta situação e mencionam o processo de produção 
spostas que definem o jornalismo a partir de dois elementos ou mais (23), e o quase total desaparecimento das condições sociais como elemento definidor.

Das 32 respostas analisadas, sete definiram o jornalismo a partir do processo de produção e da transmissão (a categoria, em relação ao primeiro questionário aplicado, ainda predomina nesse grupo de alunos, mas em menor número) e seis a partir do processo de produção e da função social. Os grupos 6 (transmissão e função social) e sete (processo de produção, transmissão e função social) contaram com quatro respostas cada um.

As condições sociais só foram mencionadas duas vezes. As respostas foram incluídas nos grupos 11 (condições sociais e função social) e 12 (processo de produção, condições sociais e transmissão). No primeiro caso, o jornalismo é definido como profissão que defende direitos da sociedade e, segundo o aluno, deveria ser uma instituição filantrópica. No outro caso, o conceito proposto é o seguinte:

\footnotetext{
O jornalismo é utilizado por meio de instrumentos, jornalista, repórter, meios de comunicação e outros para que a informação chegue às pessoas. Diferencia-se dos outros meios de informações, propagandas, novelas devido ao seu processo ser construído de veracidade, apurações, checagens e confiabilidade. O jornalismo não pode ser publicitário ou atender a interesses políticos, mesmo que seja somente em tese.
}

Como as condições sociais apareciam também nos grupos 8,9 , 10, 13, 14 e 15, não foram incluídas respostas nesses grupos.

As definições de jornalismo que mencionaram apenas um elemento foram assim distribuídas: a transmissão e a função social (grupos 2 e 3) apareceram em oito respostas, quatro em cada grupo, e o processo de produção (grupo 1) foi mencionado em uma resposta.

\section{As mudanças qualitativas nas respostas dos alunos}

Mudanças qualitativas, no ambiente acadêmico, provavelmente, sejam tidas como certas. As múltiplas mediações existentes em sala de aula oferecem, constroem - como indicado pelo presente trabalho e, anteriormente, por Leitão (2004 e 2005) - novas categorias sobre as quais se assenta a construção conceitual. Alguns resultados merecem atenção especial neste momento.

Nas concepções sobre o jornalismo dos alunos ingressantes, vinte e seis respostas mencionaram apenas um elemento, com predomínio da transmissão. Uma mudança significativa nas definições dos alunos que iniciavam o segundo período é o predomínio de respostas que integram mais de um elemento ao 
definir o jornalismo: vinte e nove respostas. Quando o questionário foi aplicado pela segunda vez foram dezenove respostas e, pela última vez, vinte e três respostas. Esse resultado se coaduna com aquele encontrado nos livros da bibliografia básica do primeiro ano do curso. Nesses livros, predominam, em sua quase totalidade, definições de jornalismo que integram dois elementos ou mais. Também se revela significativa a complexidade do processo de construção conceitual, uma vez que essa correspondência entre os conceitos de autores e de alunos não significa uma transposição dos elementos que constituem as definições, pois, se na definição dos autores predominam o processo de produção e a função social, nas definições dos alunos predominam o processo de produção e a transmissão.

Ainda que a definição de jornalismo tenha se tornado mais complexa, a ênfase sobre o processo de produção, sobre a transmissão e sobre a função social se manteve. As condições sociais só predominam no segundo questionário aplicado aos alunos do segundo período. Se a leitura do texto $A$ influência do jornalismo de Pierre Bourdieu (1997) foi decisiva para que os alunos incorporassem as condições sociais em seus conceitos, o último questionário revelou que o impacto da leitura não concretizou efeitos duradouros. As respostas ao último questionário, aplicado um mês e meio após o segundo, praticamente desconsideraram as condições sociais ao definirem o jornalismo.

Outro resultado que merece atenção é que não se mencionou em nenhum momento a perspectiva do indivíduo envolvido no processo de comunicação. O jornalismo é definido basicamente a partir de características do processo de produção (em alguns casos, são mencionadas características dos meios de comunicação), da transmissão (elemento que predomina nas respostas dos alunos ingressantes e que, nas respostas dos alunos do segundo período, vai aparecer combinado com o processo de produção) e, finalmente, da função social. Diante da complexidade que caracteriza o processo de comunicação (Wolf, 2003), fica a tarefa de conceituar o jornalismo a partir dessa complexidade, sem dissolver a especifidade do jornalismo nas condições sociais (Genro Filho, 1997), mas sem se esquecer dessas condições. Ou ainda, sem atribuir poder demais ao jornalismo em detrimento da perspectiva dos indivíduos que também atuam na construção do sentido das mensagens jornalísticas.

\section{Referências}

BARBEIRO, H. Manual de telejornalismo. Rio de Janeiro: Editora Campus, 2002.

BOURDIEU, P. A influência do jornalismo. In: BOURDIEU, P. Sobre a televisão. 
Trad. M. L. Machado. Rio de Janeiro: Jorge Zahar Editor, 1997. (p.99-120). CURADO, O. A notícia na $T V$ - o dia-a-dia de quem faz telejornalismo. São Paulo: Alegro, 2002.

ERBOLATO, M. Técnicas de codificação em jornalismo. São Paulo: Editora Ática, 1991.

GENRO FILHO, A. (1987) O segredo da pirâmide/Para uma teoria marxista do jornalismo. Revista da Fenaj, ano I, n. 1, “pag. irreg.”, 1996.

HEDGECOE, J. Guia completo de fotografia. São Paulo: Martins Fontes, 1996.

HOHLFELDT, A. Hipóteses contemporâneas de pesquisa em comunicação. In: HOHLFELDT, A.; MARTINO, L. C. e FRANÇA, V. V. (Orgs.). Teorias da comunicação/Conceitos, escolas e tendências. 3.ed. Petrópolis: Vozes, 2003. (p.187-240).

LEITÃO, S. Argumentação e construção do conhecimento: a dimensão auto-reguladora da argumentação. Vitória: X Simpósio da Associação de Pesquisa e Pós-graduação em Psicologia (Anpepp), 2004. 7p. (Mimeogr.). LEITÃO, S. Argumentação e processos de construção do conhecimento. Recife: Faculdade de Psicologia da Universidade Federal de Pernambuco, 2005. 20p. (Mimeogr.).

LIMA, I. Fotojornalismo brasileiro: realidade e linguagem. Ed. Fotografia Brasileira, 1989.

MACHADO, A. A ilusão especular. São Paulo: Brasiliense, 1984.

MORAIS, F. Chatô: o rei do Brasil. São Paulo: Cia. das Letras, 1994.

OLIVEIRA, S. M. de M. Linguagem, ideologia e conhecimento: novas perspectivas para se compreender o jornalismo. Campinas, 2006. Dissertação (Mestrado em Educação) - Faculdade de Educação, Universidade Estadual de Campinas.

PATERnOSTRO, V. Í. O texto na tv - Manual de telejornalismo. Rio de Janeiro: Campus, 1999.

SHERWOOD, H. C. A entrevista jornalística. São Paulo: Mosaico, 1981. SODRÉ, N. W. História da imprensa no Brasil. Rio de Janeiro: Maud, 2002.

SOUSA, J. P. Elementos de jornalismo impresso. Florianópolis: Letras Contemporâneas, 2005.

TRAQUINA, N. Teorias do jornalismo, porque as noticias são como são. v. 1. 2 ed. Florianópolis: Insular, 2005.

TELES, J. M. A imprensa matutina. Goiânia: Cerne, 1986.

WOLF, M. Teorias das comunicações de massa. Trad. K. Jannini. 2.ed. São Paulo: Martins Fontes, 2005.

Recebido em 13 de fevereiro de 2009 Aprovado em 4 de maio de 2009 